\title{
Clinical Learning Environment and Supervision: Satisfaction Levels of University of Rwanda Students
}

\author{
Catherine Musabyimana ${ }^{1 *}$, Juliet Norah Mukankusi ${ }^{1}$, Theogene Nyandwi ${ }^{2}$, John Mugarura ${ }^{3}$, Anita Collins ${ }^{1,4}$ \\ ${ }^{1}$ School of Nursing and Midwifery, University of Rwanda, College of Medicine and Health Sciences, Kigali, Rwanda. \\ ${ }^{2}$ Department of Physiotherapy and Directorate of Research and Innovation, University of Rwanda, College of Medicine and Health \\ Sciences, Kigali, Rwanda. \\ ${ }^{3}$ Centre for Teaching and Learning Enhancement, University of Rwanda, College of Medicine and Health Science, Kigali, Rwanda. \\ ${ }^{4}$ Rory Meyers College of Nursing, New York. University, New York, USA.
}

*Corresponding author: Catherine Musabyimana. School of Nursing and Midwifery, College of Medicine and Health Sciences, University of Rwanda, Remera Campus, 11 KG 47, Kigali, Rwanda, Email: cathymusabyimana@gmail.com

\begin{abstract}
Background

Nursing and midwifery students need to learn theoretical knowledge and practical skills. Students are satisfied with a clinical education program when the environment is conducive to acquiring the knowledge, skills and professional attitude essential for their career.

Objective

To assess the level of satisfaction with the clinical learning environment among nursing and midwifery students at the University of Rwanda.

\section{Methods}

A descriptive cross-sectional study design was used to assess 280 undergraduate nursing and midwifery students. The study used the instrument entitled, the 'Clinical Learning Environment Supervision and Nurse Teacher Tool' (CLES+T). Data analysis used descriptive statistics.

\section{Results}

The majority of participants were highly satisfied with the clinical learning environment (58\%), ward atmosphere (54\%), the leadership of ward manager (58\%) and supervisory relationship (62\%). Chi-square results showed a significant association between class level $(\mathrm{p}=0.001)$ and last clinical placement $(\mathrm{p}=0.000)$. Some students $(7 \%)$ were dissatisfied with the supervisory relationship.

\section{Conclusion}

Most nursing and midwifery students were satisfied with the clinical learning environment. However, the reported levels of dissatisfaction showed that improvements are needed to attain a quality education and meet the Sustainable Development Goal (SDG) Four: to ensure inclusive and equitable quality education and promote lifelong learning opportunities for all.
\end{abstract}

Rwanda J Med Health Sci 2019;2(2):194-201.

\section{Keywords: Clinical placement, learning,student, satisfaction, nursing, midwifery}

\section{Background}

A clinical learning environment (CLE) is a setting where clinical skills are learned with direct or distant supervision.[1] In the nursing profession, the CLE is an essential component for competence development and integration of theoretical knowledge, clinical practice, and professionalism.[2-4] An effective learning process in the clinical setting is essential to combine cognitive, psychomotor and appropriate attitudes in such a way to benefit both the learning needs of the student and the nursing care needs of the client. [5]

Historically, nursing education in Rwanda started in the colonial period, and informal training was conducted by religious institutions to meet the basic care needs of the population.[6] Later, nursing education became more structured and integrated formally into six years of secondary education, [7] and hospital-based.[6] After the 1994 genocide against Tutsis, nursing education at the secondary level was replaced by education in academic institutions.[7,8] Habimana and colleagues[9] provided a comprehensive assessment of the different teaching models in Rwanda. Currently, clinical teaching utilises the facilitation/supervision model, in which facilitators are university-employed faculty and responsible for both students' summative and formative clinical assessments, and involving simulation in the skills laboratory to develop practical skills.[9]

As nursing education evolved, the clinical settings continued to be recognised as essential areas for students 
to develop competencies at various health facilities.[5] Health facilities are learning environments whereby clinicians, patients, mentors and nurse educators collaborate to ensure clinical teaching and learning. [10] Teaching in health facilities is typically more cumbersome than the classroom or skills laboratory; however, students benefit significantly from learning in a complex clinical context, with the influence of social relationships in the real world.[1]

Numerous researchers have explored the various factors that contributed to successful skills acquisition during clinical placement.[10-18] There are three main learning domains affecting student nurses and midwives; ward atmosphere (WA), the leadership of the ward manager (WM), and supervisory relationship with nurse teacher (NT). Clinical placements offer challenges for students, where by problem-solving skills become part of the learning process.[13] Enabling environments that allow students to feel supported in the clinical placement provides students with more confidence and allows them to take the initiative within a safe limit.[15] Such an environment assumes that the three domains would provide the necessary tools for a clinical environment conducive to learning. Historically in Rwanda, the CLE in nursing education context has lacked the necessary tools with insufficient role models, teachers, and mentors in the clinical setting. $[7,14]$

There is a paucity of research related to clinical placement satisfaction in Rwanda. The research findings will contribute to the limited body of knowledge on clinical teaching, and will serve as a baseline for students' satisfaction. Furthermore, the study will help form an integrative model whereby nurses and midwives in the clinical setting are part of the supervisory team, leading to more collaboration and partnerships between nursing schools and health facilities. In addition to nursing education, the study findings will also be useful to nursing practice, administration, and further research. The study aimed to assess the level of satisfaction with the CLE among nursing and midwifery students at the University of Rwanda.

\section{Methods}

\section{Design}

A descriptive cross-sectional design was used to assess the level of satisfaction among undergraduate nurses and midwives in the clinical learning environment. The study was conducted at the School of Nursing and Midwifery on the six campuses at the University of Rwanda.

\section{Participants' recruitment}

The sample framework included 782 nursing and midwifery students enrolled in programs at the six campuses at the University of Rwanda. The proportionate sampling method was used to obtain a representation of all campuses, and a sample size of 264 students was calculated using theTaro Yamane formula.
[16] The study sample included 280 full-time continuing students, registered in the nursing or midwifery program in the 2016-2017 academic year, and currently in Year Two to Year Four. The sample population was therefore equipped with experience in a prior clinical placement. To minimise a low response rate through attrition, we added $10 \%$ to the sample size and distributed 290 questionnaires. Among 290 participants, only 280 returned the questionnaire. The study was conducted from 1 February to 31 July 2017.

\section{Measures}

The gold standard of a clinical learning environment, according to international research, is the CLE and Supervision plus Nurse Teacher scale (CLES+T). This study used the CLES+T tool developed and revised by Saarikoski.[17] The questionnaire was modified minimally to make it more understandable in Rwanda. The internal consistency was measured with Cronbach's alpha of 0.70 , initially with a range of 0.63 to 0.83 . The instrument used a self-reporting questionnaire with two sections and 35 items:

Section 1: Demographic characteristics (6 questions)

Section 2: Three learning domains: ward atmosphere (9 questions), the leadership of the ward manager (8 questions), supervisory relationship with nurse teacher (12 questions).

Each question was scored from 1 to 5 based on the Likert scale, whereby 1 corresponded to 'fully disagree,' 2 'disagree to some extent,' 3 'neither agree nor agree,' 4 'agree to some extent,' and 5 'fully agree'.[12] particularly in the areas of clinical teaching and the development of a more 'academic' role for nurse teachers. The data $(n=558$ Therefore, the scores for each domain were as follows: ward atmosphere (9-45 points), the leadership of the ward manager (8-40 points), supervisory relationship (12-60 points). The scores were then displayed as a percentage based on the participants' satisfaction. The lowest level of student' satisfaction was $\leq 49 \%$, moderate level of student' satisfaction ranged between $50 \%$ and $74 \%$, while the highest level of student' satisfaction was $75 \%$ and $100 \%$.

\section{Data collection}

We approached teachers about the research, who in turn contacted the class representatives about arranging a time to conduct the study. The class representative sent messages to students giving some information about the study before the next class session. From the class lists, we selected every second person until the sample size reached the desired quota of participants from each campus. Participants who accepted to participate signed an informed consent knowing that confidentiality would be respected. The selfadministered questionnaire was given to the participants and took about 30 minutes to complete. We collected the completed questionnaires within 24 hours. 


\section{Data analysis}

Descriptive statistics were used to analyse the data. Sociodemographics were assessed using frequencies. Chi-square test assessed the association between sociodemographic variables and the ward atmosphere, leadership of the ward manager and supervisory relationship. The significance level was set at $\mathrm{p} \leq 0.05$. The data were managed by SPSS version 18 .

\section{Ethical considerations}

The University of Rwanda, College of Medicine and Health Sciences Institutional Review Board approved the study. Informed consent was obtained, and confidentiality and anonymity assured. Participants were aware that the study was voluntary and that involvement would have no impact on their university grades.

\section{Results}

\section{Demographic data}

The results showed that the majority of participants were female $(52.1 \%)$, aged 20 to 24 years $(92.1 \%)$, and nursing students $(61.4 \%)$ (table 1$)$. The majority of participants were at Level Two in the nursing or midwifery program (56.1\%), attended a health centre for the last clinical learning site $(55.7 \%)$, and located at Nyarugenge campus $(32.9 \%)$.

Table 1. Sociodemographic characteristics $(n=280)$

\begin{tabular}{ll}
\hline Sociodemographics & $\mathbf{n}(\mathbf{\%})$ \\
\hline Gender & \\
Female & $146(52.1)$ \\
Male & $134(47.9)$ \\
Ages (years) & \\
$\leq 19$ & $4(1.4)$ \\
20 to 24 & $258(92.1)$ \\
$25-29$ & $16(5.7)$ \\
$\geq 30$ & $2(0.7)$ \\
Department & $172(61.4)$ \\
Nursing & $108(38.6)$ \\
Midwifery & \\
Class level (Year) & $157(56.1)$ \\
2 & $105(37.5)$ \\
3 & $18(6.4)$ \\
4 & \\
Last clinical learning site & $156(55.7)$ \\
Health center & $106(37.9)$ \\
District hospital & $18(6.4)$ \\
Referral hospital & \\
Campus & $30(10.7)$ \\
Byumba & $34(12.1)$ \\
Kabagyi & $43(15.4)$ \\
Kibungo & $32(11.4)$ \\
Nyagatare & $92(32.9)$ \\
Nyarugenge & $49(17.5)$ \\
Rwamagana & \\
& \\
\hline
\end{tabular}

\section{Clinical learning environment}

Results showed that the majority of participants $(54 \%)$ had a high level of satisfaction with the ward atmosphere, nearly half (41\%) had a moderate level, and a few $(5 \%)$ had a low level (table 2) Over a third (40\%) were satisfied that it was a good learning environment, and nearly half $(45.7 \%)$ agreed to some extent that the staff was easy to approach. Other results indicated that nearly half thought there weresufficient learning opportunities $(42.1 \%)$, and nearly three quarters $(70.4 \%)$ agreed or agreed to some extent that it was a positive ward atmosphere.

Some other participants were less satisfied revealing low percentage scores (table 2). They either fully disagreed or disagreed to some extent, for example; less than a quarter of the participants were comfortable at staff meetings (20.3\%), though staff learned students' names $(19.2 \%)$, staff were interested in supervision $(19.6 \%)$, and the ward atmosphere was positive $(10 \%)$. 
Table 2. Satisfaction with Ward Atmosphere $(n=280)$

\begin{tabular}{lcllll}
\hline Ward Atmosphere & $\begin{array}{l}\text { Fully } \\
\text { disagree } \\
\mathbf{n}(\%)\end{array}$ & $\begin{array}{l}\text { Disagree } \\
\text { to some } \\
\text { extent } \\
\mathrm{n}(\%)\end{array}$ & $\begin{array}{l}\text { Neither } \\
\text { agree nor } \\
\text { disagree } \\
\mathrm{n}(\%)\end{array}$ & $\begin{array}{l}\text { Agree } \\
\text { to some } \\
\text { extent } \\
\mathrm{n}(\%)\end{array}$ & $\begin{array}{c}\text { Fully } \\
\text { agree } \\
\mathbf{n}(\%)\end{array}$ \\
\hline Staff were easy to approach & $17(6.1)$ & $30(10.7)$ & $50(17.9)$ & $128(45.7)$ & $55(19.6)$ \\
Comfortable at start of shift & $10(3.6)$ & $23(8.2)$ & $55(19.3)$ & $104(37.1)$ & $89(31.8)$ \\
Comfortable at staff meetings & $23(8.2)$ & $34(12.1)$ & $64(22.9)$ & $96(34.3)$ & $63(22.5)$ \\
Positive ward atmosphere & $11(3.9)$ & $17(6.1)$ & $55(19.3)$ & $127(45.4)$ & $70(25.0)$ \\
Staff interested in supervision & $13(4.6)$ & $42(15.0)$ & $58(20.7)$ & $98(35.0)$ & $69(24.6)$ \\
Staff learned student's names & $20(7.1)$ & $34(12.1)$ & $43(15.4)$ & $99(35.4)$ & $84(30.0)$ \\
Sufficient learning situations & $8(2.9)$ & $31(11.1)$ & $66(23.6)$ & $118(42.1)$ & $57(20.4)$ \\
Multi-dimensional content & $5(1.8)$ & $41(14.6)$ & $65(23.2)$ & $121(43.2)$ & $48(17.1)$ \\
Good learning environment & $4(1.4)$ & $31(11.1)$ & $48(17.1)$ & $85(30.4)$ & $112(40.0)$ \\
& & & & &
\end{tabular}

Nearly half $(43.6 \%)$ fully agreed that the ward manager was a team member and another third (32.5\%) agreed to some extent (table 3). A third agreed that the nursing documentation was clear $(33.2 \%)$ and another third $(33.9 \%)$ agreed to some extent. Nearly a third (30\%) agreed the patients received individual nursing care, and over another third (40\%) agreed to some extent.
Others either fully disagreed or disagreed to some extent, as shown with low percentage scores (table 3). Less than a quarter of the participants thought the ward manager regarded the staff as key resources (15.7\%), the ward's nursing protocols were clearly defined $(19.3 \%)$, there were no problems in the information flow related to patients' care $(18.9 \%)$, documentation of nursing was clear (18.5\%).

Table 3. Leadership of the Ward Manager $(n=280)$

\begin{tabular}{|c|c|c|c|c|c|}
\hline Leadership style of WM & $\begin{array}{l}\begin{array}{l}\text { Fully } \\
\text { disagree }\end{array} \\
n(\%)\end{array}$ & $\begin{array}{l}\text { Disagree } \\
\text { to some } \\
\text { extent } \\
\mathrm{n}(\%)\end{array}$ & $\begin{array}{l}\text { Neither } \\
\text { agree nor } \\
\text { disagree } \\
\mathrm{n}(\%)\end{array}$ & $\begin{array}{l}\text { Agree } \\
\text { to some } \\
\text { extent } \\
\mathrm{n}(\%)\end{array}$ & $\begin{array}{l}\text { Fully } \\
\text { agree } \\
\mathrm{n}(\%)\end{array}$ \\
\hline WM regarded staff as key resource & $11(3.9)$ & $33(11.8)$ & $57(20.4)$ & $104(37.1)$ & $75(26.8)$ \\
\hline WM was a team member & $6(2.1)$ & $21(7.1)$ & $40(14.3)$ & $91(32.5)$ & $122(43.6)$ \\
\hline WM feedback a learning situation & $4(1.4)$ & $27(9.6)$ & $61(21.8)$ & $112(40)$ & $76(27.1)$ \\
\hline Individual staff effort appreciated & $6(2.1)$ & $28(10)$ & $57(20.4)$ & 108(38.6) & $81(28.9)$ \\
\hline $\begin{array}{l}\text { Ward's nursing protocols } \\
\text { clearly defined }\end{array}$ & $12(4.3)$ & $42(15)$ & $56(20)$ & 104(37.1) & $66(23.6)$ \\
\hline Patients received individual nursing care & $12(4.3)$ & $27(9.6)$ & $45(16.1)$ & $112(40)$ & $84(30.0)$ \\
\hline $\begin{array}{l}\text { No problems with flow of } \\
\text { patient care information }\end{array}$ & $14(5.0)$ & $39(13.9)$ & $48(17.1)$ & $121(43.2)$ & $58(20.7)$ \\
\hline Clear nursing documentation & $13(4.6)$ & $39(13.9)$ & $40(14.3)$ & $95(33.9)$ & $93(33.2)$ \\
\hline
\end{tabular}

The majority $(76.1 \%)$ agreed $(37.9 \%)$ or agreed to some extent $(38.2 \%)$, that the nurse teacher (NT) was like a member of the nursing team (table 4). In contrast, nearly a quarter $(23.9 \%)$ disagreed or could not decide if the nurse teacher was like a member of the nursing team. The majority $(68.3 \%)$ agreed $(35.4 \%)$ or agreed to some extent $(32.9 \%)$, that they continuously received feedback from the supervisor (table 4). In contrast, nearly a third $(31.7 \%)$ disagreed or could not decide if they continuously received feedback from the supervisor.

Over a third $(41.8 \%)$ indicated they fully disagreed, or disagreed to some extent, with the following (table 4): the supervisory relationship was characterized by a sense of trust (10.4\%), NT was capable of integrating theoretical knowledge at every practice of nursing $(15.7 \%)$, and NT helped supervisees to reduce the theory-practice gap (15.7\%). Others either fully disagreed or disagreed to some extent, that they received individual supervision $(23.9 \%)$, continuously received feedback from supervisor $(17.2 \%)$, and NT gave pedagogical expertise to the clinical team $(12.1 \%)$. Furthermore, others could not decide whether to agree or disagree that there were mutual respect and approval $(22.5 \%)$ or mutual interaction $(20 \%)$ within the supervisory relationship. 
Table 4. Supervisory relationship with Nurse Teacher $(n=280)$

\begin{tabular}{|c|c|c|c|c|c|}
\hline $\begin{array}{l}\text { Supervisory relationship } \\
\text { with NT }\end{array}$ & $\begin{array}{l}\begin{array}{l}\text { Fully } \\
\text { disagree }\end{array} \\
\mathrm{n}(\%)\end{array}$ & $\begin{array}{l}\text { Disagree } \\
\text { to some } \\
\text { extent } \\
\mathrm{n}(\%)\end{array}$ & $\begin{array}{l}\text { Neither } \\
\text { agree nor } \\
\text { disagree } \\
\mathrm{n}(\%)\end{array}$ & $\begin{array}{l}\text { Agree } \\
\text { to some } \\
\text { extent } \\
\mathrm{n}(\%)\end{array}$ & $\begin{array}{l}\text { Fully } \\
\text { agree } \\
\mathrm{n}(\%)\end{array}$ \\
\hline $\begin{array}{l}\text { My supervisor shows a positive } \\
\text { attitude towards supervision }\end{array}$ & $12(4.3)$ & $18(6.4)$ & $36(12.9)$ & $129(46.1)$ & $85(30.4)$ \\
\hline $\begin{array}{l}\text { I felt that I received individual } \\
\text { supervision }\end{array}$ & 41(14.6) & $26(9.3)$ & $59(21.1)$ & $101(36.1)$ & $53(18.9)$ \\
\hline $\begin{array}{l}\text { I continuously received supervisory } \\
\text { feedback }\end{array}$ & $15(5.4)$ & $33(11.8)$ & $41(14.6)$ & $92(32.9)$ & $99(35.4)$ \\
\hline $\begin{array}{l}\text { Supervisory relationship based on } \\
\text { equality and promoted learning }\end{array}$ & 13(4.6) & $33(11.8)$ & $41(14.6)$ & $98(35)$ & $95(33.9)$ \\
\hline $\begin{array}{l}\text { Mutual interaction within supervisory } \\
\text { relationship }\end{array}$ & $14(5)$ & $29(10.4)$ & $56(20)$ & $110(39.3)$ & $71(25.4)$ \\
\hline $\begin{array}{l}\text { Mutual respect and approval within } \\
\text { supervisory relationship }\end{array}$ & $6(2.1)$ & $28(10)$ & $63(22.5)$ & $116(41.4)$ & $67(23.9)$ \\
\hline $\begin{array}{l}\text { Supervisory relationship characterized } \\
\text { by trust }\end{array}$ & $10(3.6)$ & $19(6.8)$ & $41(14.6)$ & $118(42.1)$ & $92(32.9)$ \\
\hline $\begin{array}{l}\text { NT able to integrate theoretical } \\
\text { knowledge in to every practice }\end{array}$ & $9(3.2)$ & $35(12.5)$ & $40(14.3)$ & 104(37.1) & $92(32.9)$ \\
\hline $\begin{array}{l}\text { NT operationalized learning goals in } \\
\text { clinical placement }\end{array}$ & $7(2.5)$ & $24(8.6)$ & $47(16.8)$ & $118(42.1)$ & $84(30.0)$ \\
\hline $\begin{array}{l}\text { NT helped reduce theory-practice } \\
\text { gap }\end{array}$ & $9(3.2)$ & $35(12.5)$ & $40(14.3)$ & 104(37.1) & $92(32.9)$ \\
\hline NT like member of nursing team & $16(5.7)$ & $13(4.6)$ & $38(13.6)$ & 107(38.2) & $106(37.9)$ \\
\hline $\begin{array}{l}\text { NT gave pedagogical expertise to } \\
\text { clinical team }\end{array}$ & 13(4.6) & $21(7.5)$ & $46(16.4)$ & $119(42.5)$ & $81(28.9)$ \\
\hline
\end{tabular}

\section{Discussion}

The study results showed a near balance between female $(52.1 \%)$ and male $(47.9 \%)$ students registered in nursing and midwifery programs, attesting to the success of a gender balance policy at the University of Rwanda. This gender equality situation is in contrast to the historical background of Florence Nightingale and her perception and feminisation that nursing was a female profession. [18] In contemporary nursing in other settings, male nurses constitute about $10 \%$ of nursing professionals. [19]

Based on age, most participants were between 20 to 24 years; this is relatively common as they join university after six years of secondary school. The highest representation of students was from Nyarugenge campus, which is congruent with the large number enrolled (246) according to the academic registrar's list, while the lowest number of nursing and midwifery students (84) were from the Byumba campus.

\section{Satisfaction with ward atmosphere}

Based on the satisfaction classification, the results showed that over half (54\%) were highly satisfied, many were moderately satisfied (41\%), and a few $(5 \%)$ had a low satisfaction score. Nearly three quarters (73\%), with a mean score of 33 , were situated in the moderate class level of satisfaction with the ward atmosphere. The satisfaction results were similar to a study of 310 undergraduate nursing students in Oman in the Middle East, [12] which did not identify the satisfaction classification level. To be satisfied at a high level, students should be comfortable with the ward atmosphere, according to a study of 103 nursing students in the Caribbean,[20] as the ward atmosphere plays a vital role in students' satisfaction.[12]

The findings revealed that less than half $(40 \%)$ of the participants fully agreed and were therefore satisfied; however, $40 \%$ is not enough for students satisfaction, it should be $50 \%$ or higher. It means there is room for improvement in the clinical learning environment (CLE), mostly in the area of nursing teamwork.[21] No statistical significance between the demographic data and ward atmosphere $(\mathrm{p}>0.05)$ was identified. Another study indicated that the clinical atmosphere made learning problematic to achieve the objectives for 
students in Sweden.[22] This factor may result in lower student's acceptance within the nursing team and as in our study, not feeling welcome at staff meetings.[18,19] This type of environment provides fewer opportunities to learn and grow through real-world experiences in the clinical setting.[20]

\section{Satisfaction with ward manager leadership style}

Despite that, the majority (58\%) were highly satisfied with the WM leadership style, the remaining (42\%) showed dissatisfaction with the CLE and a need for improvement. Another study of nursing students in their final year of the nursing program in Sweden showed a positive experience with the WM.[22] Other studies demonstrated the ward as a good learning environment $(p<0.001) \cdot[18,23]$ Therefore, the participants in the same studies showed that the learning environment was scored more negatively than the hospital-based learning environment.

The students were in disagreement with two statements; there were no problems in the information flow related to patient care $(18.9 \%)$, and documentation of nursing was clear (18.5\%), indicating satisfaction with the WM leadership of less than $76 \%$. Similarly, a study conducted in Sweden with 260 nursing students who gave the WM leadership the lowest score.[23] For nursing and midwifery students to be satisfied, the WM should actively engage the nursing team in the students' education. $[10,24,25]$

Gender was the only demographic characteristic significantly associated with the WM leadership style $(p=0.005)$. This finding concurs with the historical background of females dominating the nursing education in Rwanda.[25] This factor is not surprising considering the majority of participants were female $(52.1 \%)$ as are the majority of nursing leaders in Rwandan clinical placements, similar to the historical background.

\section{Satisfaction with supervisory relationship}

The majority $(62 \%)$ was highly satisfied or moderately satisfied $(31 \%)$ with the supervisory relationship, though some $(7 \%)$ were not satisfied. The study showed a significant association between the supervisory relationships with two demographic characteristics; class level $(\mathrm{p}<0.001)$, and the last clinical placement $(\mathrm{p}<0.000)$.

To become a competent nurse or midwife, a student should be satisfied with all domains of CLE, but in particular, the supervisory relationship as they acquire knowledge, skills and a good attitude to ascend from novice to expert clinician. [26] This factor requires close supervision and good role models, which concurs with the significant association between demographics and supervisory relationship for the class level $(p=0.001)$ and the last clinical placement $(\mathrm{p}=0.000)$. The NT guides students through the CLE through a wide range of objectives, including reflecting, debriefing, collaboration with staff and patients, involvement in ward activities, and evaluating competency development.[27]

Some participants responded negatively and disagreed with $10-40 \%$ of the statements. Similarly, a study conducted in the United States,[26] showed the supervisory relationship was problematic with over half $(59.4 \%)$ indicating they did not have individual supervision or only experienced it one or two times during the clinical placement. Students attending a clinical placement at government hospitals as opposed to private facilities had a higher rate of satisfaction in Nepal.[28]

The current results indicated that at every class level and clinical placement there was a need for individual student supervision. Similarly, a study of nursing students in their final year at three universities in Sweden discovered that the students had a more positive experience when they were with the same clinical preceptor, instead of a different preceptor each day.[29] Supervision was achieved through a group of students with a facilitatorstudent ratio of $1: 6$, or 1:8 or more.[29]

Consequently, there was a need to improve the supervisory relationship, based on the following disagreeing responses: Supervisors had a positive attitude towards supervision (10.7\%), the student continuously received supervisory feedback (17.2\%), the NT had the capability to integrate theoretical knowledge and practice $(15.7 \%)$, the NT helped me to reduce the theory-practice gap $(15.7 \%)$, and the student felt they received individual supervision $(23.9 \%)$.

\section{Limitations}

This study focused on nursing and midwifery students at the University of Rwanda and therefore cannot be generalised to other universities or students in other programs. Since it is a public school of Nursing and Midwifery, findings from a private facility may be different. The data collection period was throughout the semester, so there may be recall bias. Some students may not have been truthful for fear of reprisal since they were still in school. Results might be different at the end of the term or when students have graduated and already have their certificate.

\section{Future research}

A study is needed to explore the various factors that influence students' satisfaction in the CLE, such as, type of health facility, nursing ward, nursing organisation, and nurse educators. The identified factors could then be translated into clinical teaching to improve environmental and supervisory style. The University of Rwanda, faculty and students in the Master of Science in Nursing programme, could initiative and develop an 
annual survey to help guide the content of clinical instruction. Another study could focus on nursing and midwifery staff in the hospitals and discover their reasons for supporting students, or not, in the clinical setting.

\section{Conclusion}

This study aimed to assess the level of satisfaction with the CLE among nursing and midwifery students at the University of Rwanda. The findings indicated that the majority of students were satisfied with the CLE. Students expressed satisfaction with the supervisory relationship, regularity of individualised meetings, supporting the presence of the nurse teacher, sense of teamwork, and a well-structured nursing care environment. Other students were dissatisfied and expecting more than what they received. This factor indicates a need for improvement to attain a quality education and for Rwanda to meet the Sustainable Development Goal (SDG) Four: to ensure inclusive and equitable quality education and promote lifelong learning opportunities for all.

\section{Acknowledgements}

We are thankful to Mikko Saarikoski for the permission of using the CLES+T tool, to the students who participated in the study, to Dr Pamela Meharry for her support with this publication through the writing retreats and later reviewing the manuscript, and to Dr. Geldine Chironda for her support in the statistical analysis.

This article is published open access under the Creative Commons Attribution-NonCommercial NoDerivatives (CC BY-NC-ND 4.0). People can copy and redistribute the article only for noncommercial purposes and as long as they give appropriate credit to the authors. They cannot distribute any modified material obtained by remixing, transforming or building upon this article. See https:// creativecommons.org/licenses/by-nc-nd/4.0/

\section{References}

1. Haraldseid C, Friberg F, Aase K. Nursing students' perceptions of factors influencing their learning environment in a clinical skills laboratory: A qualitative study. Nurse Educ Today 2015; 35: e1-e6.

2. Bigdeli S, Pakpour V, Aalaa M, et al. Clinical learning environments (actual and expected): Perceptions of Iran University of Medical Sciences nursing students. Med J Islam Repub Iran; 29. Epub ahead of print 2015. DOI: 10.1157/13109655.

3. Antohe I, A, Riklikiene O, et al. Clinical education and training of student nurses in four moderately new European Union countries: Assessment of students' satisfaction with the learning environment. Nurse Educ Pract 2016; 17: 139-144.

4. Chan DSK, Ip WY. Perception of hospital learning environment: A survey of Hong Kong nursing students. Nurse Educ Today 2007; 27: 677-684.

5. Alexis, Harerimana, et al. Historical Overview of Nursing and Midwifery Education and Nursing Workforce in Rwanda. Br J of Med Heal Res; 2. Epub ahead of print 2015. DOI: ISSN: 2394 - 2967.

6. Harelimana A, Mtshali N, Mukamana D, et al. Historical Overview of Nursing and Midwifery Education and Nursing Workforce in Rwanda. Bjmhr 2015; 2: 1-10.

7. Mukamana D, Uwiyeze G, Sliney A. Nursing and Midwifery Education in Rwanda : Telling our Story. Rwanda J Ser F Med Heal Sci 2015; 2: 9-12.

8. D Mukamana, G Uwiyeze AS. Nursing and Midwifery Education in Rwanda: Telling our Story. Rwanda J; 2. Epub ahead of print 2015. DOI: http://dx.doi.org/10.4314/rj.v2i2.1F.

9. Amos Habimana, Malachie Tuyizere PU. Clinical supervision of nursing students: challenges and alternatives. Rwanda J; 3. Epub ahead of print 2016. DOI: http://dx.doi.org/10.4314/rj.v3i1.7F.

10. Jessee MA. Influences of Sociocultural Factors Within the Clinical Learning Environment on Students' Perceptions of Learning: An Integrative Review. J Prof Nurs 2016; 32: 463-486.

11. Warne T, Johansson U-B, Papastavrou E, et al. An exploration of the clinical learning experience of nursing students in nine European countries. Nurse Educ Today 2010; 30: 809-815.

12. Tomietto M, Comparcini D, Saarikoski M, et al. Multilevel perspectives in clinical learning environments' assessment: An insight on levels involved in planning nursing education. J Nurs Educ Pract 2014; 4: 42-50.

13. Helgesen AK, Gregersen AG, Roos AKØ. Nurse students' experiences with clinical placement in outpatient unit - a qualitative study. BMC Nurs 2016; 15: 49.

14. Warne T, Johansson U-B, Papastavrou E, et al. An exploration of the clinical learning experience of nursing students in nine European countries. Nurse Educ Today 2010; 30: 809-815.

15. Hakim A. Nursing students' satisfaction about their field of study. J Adv Med Educ Prof 2014; 2: 82-7.

16. Israel G. Determinig sample size. 1992; 1-5.

17. Saarikoski M, Leino-Kilpi H, Warne T. Clinical 
learning environment and supervision: testing a research instrument in an international comparative study. Nurse Educ Today 2002; 22: 340-9.

18. D’Souza MS, Karkada SN, Parahoo K, et al. Perception of and satisfaction with the clinical learning environment among nursing students. Nurse Educ Today 2015; 35: 833-840.

19. Onuoha PC, Prescott CK, Daniel E. Factors associated with nursing students' level of satisfaction during their clinical experience at a major Caribbean hospital. Asian J Sci Technol 2016; 7: 2944-2954.

20. Bisholt B, Ohlsson U, Engström AK, et al. Nursing students' assessment of the learning environment in different clinical settings. Nurse Educ Pract 2014; 14: 304-310.

21. Marco Tomietto, Dania Comparcini, Mikko Saarikoski, Valentina Simonetti GC. Multilevel perspectives in clinical learning environments' assessment: An insight on levels involved in planning nursing education. J Nurs Educ Pract; 4. Epub ahead of print 2014. DOI: https://doi.org/10.5430/jnep. v4n12p42.

22. Skaalvik MW, Normann HK, Henriksen N. Clinical learning environment and supervision: Experiences of Norwegian nursing students - a questionnaire survey. J Clin Nurs 2011; 20: 2294-2304.
23. Saarikoski M, Leino-Kilpi H WT. Clinical learning environment and supervision: testing a research instrument in an international comparative study. Nurse Educ Today 2002; 22: 340-349.

24. Bigdeli, Shoaleh; Pakpour, Vahid; Aalaa, Maryam; Sanjari, Mahnaz; Shekarabi, Robabeh; Haghani, Hamid; Mehrdad N. Clinical learning environments (actual and expected): perceptions of Iran University of Medical Sciences nursing students. Med J Islam Repub Iran 2015; 29: p1-8. 8p.

25. Murebwayire M, Biroli I, Ewing H. The Evolution of the Nursing Profession Post Genocide. Rwanda J Ser F Med Heal Sci 2015; 2: 106.

26. Oshvandi K, Moghadam AS, Khatiban M, et al. On the application of novice to expert theory in nursing; a systematic review. J Chem Pharm Sci 2016; 9: 3014-3020.

27. Sundler AJ, Björk M, Bisholt B, et al. Student nurses' experiences of the clinical learning environment in relation to the organization of supervision: A questionnaire survey. Nurse Educ Today 2014; 34: 661-666.

28. Nepal B, Taketomi K, Ito YM, et al. Nepalese undergraduate nursing students' perceptions of the clinical learning environment, supervision and nurse teachers: A questionnaire survey. Nurse Educ Today 2016; 39: 181-188. 